\section{$\underset{\substack{\text { hommes } \\ \text { \& migrations }}}{ }$}

\section{Hommes \& migrations}

Revue française de référence sur les dynamiques

migratoires

1305 | 2014

L'exil chilien en France

\title{
Un exercice de mémoire
}

\section{Roberto Romero}

Édition électronique

DOI : 10.4000/hommesmigrations.2705

ISSN : 2262-3353

\section{Éditeur}

Musée national de l'histoire de l'immigration

\section{Édition imprimée}

Date de publication : 1 janvier 2014

Pagination : 6-7

ISBN : 978-2919-040261

ISSN : $1142-852 X$

\section{Référence électronique}

Roberto Romero, «Un exercice de mémoire », Hommes \& migrations [En ligne], 1305 | 2014, mis en ligne le 01 janvier 2017, consulté le 03 mai 2019. URL : http://journals.openedition.org/ hommesmigrations/2705; DOI : 10.4000/hommesmigrations.2705 


\section{UN EXERCICE DE MÉMOIRE}

par ROBERTO ROMERO, vice-président de la région Île-de-France.

Le coup d'État du 11 septembre 1973 et les dixsept ans de dictature civico-militaire qui ont suivi ont engendré un exil politique massif suivi, dans les années 1980, d'une émigration économique non moins importante, faisant qu'un petit pays comme le Chili se retrouve aujourd'hui avec une diaspora d'environ un million de personnes dispersées dans le monde entier. L'origine de cette diaspora, qui a souvent fait souche dans les pays d'accueil, et notamment en France, est éminemment politique, et les exilés, les déracinés, les bannis dans des circonstances brutales, restent marqués à vie. L'exil forcé, involontaire, n'est pas assimilable à une immigration ni à l'expérience du cosmopolitisme, même si, quarante années après le traumatisme, il ne fait pas de doute que la culture et les modes de vie français ont modifié en profondeur la charpente intellectuelle, culturelle et sociale des Chiliens, faisant d'eux des femmes, des hommes et des enfants non seulement exilés, mais aussi cosmopolites, français, citoyens du monde. Les exilés chiliens ont vite qualifié la vie précaire lors de leur arrivée en France de "bourse Pinochet". Jamais autant de Chiliens, en effet, n'avaient eu l'occasion de résider en Europe, privilège réservé jusqu'alors aux seules élites, aux grandes familles, aux immenses fortunes latifondiaires. Et voilà qu'étudiants, ingénieurs, professeurs, assistantes sociales, musiciens, écrivains, femmes au foyer, ouvriers qualifiés, architectes, prêtres, contremaîtres du bâtiment, électriciens, libraires, peintres, militants, tous se retrouvaient en Europe, certes dans des foyers d'ac- cueil, mais pour longtemps, avec l'impérieuse obligation de réinventer leur vie. Les engagements politiques eux-mêmes, le militantisme si intense des années de l'Unité populaire, changeaient de nature de l'autre côté de l'Atlantique. Les exilés allaient devoir recomposer leurs partis, militer de loin, alors que l'action sur le terrain avait façonné leur vie quotidienne depuis des années. Les guerres d'indépendance et les guerres civiles vécues par les Chiliens tout au long du XIX ${ }^{e}$ siècle avaient certes produit des exilés, mais jamais en si grand nombre. Avant Pinochet, le gouvernement autoritaire de Gabriel González Videla (1946-1952) avait déporté les militants du Parti communiste, déclaré hors la loi, forçant le futur Prix Nobel de littérature Pablo Neruda à la clandestinité puis à l'exil : il y écrira son chef-d'œuvre, Chant général.

Deux commissions nationales, en 1990 et en 2004, ont tenté de faire un décompte officiel des victimes de la dictature. La commission Rettig, intitulée "Vérité et réconciliation", a identifié 2279 victimes de la violence politique ; la commission Valech, portant sur "la prison politique et la torture", a ajouté 34690 noms de victimes de tortures et de viols. Aucune commission officielle n'a dénombré les exilés. Des calculs croisés permettent d'avancer le chiffre de 200000 exilés au sens strict du terme, c'est-àdire sans possibilité de retour, entre 1973 et 1990 (Commission chilienne des droits de l'homme, 1983). Une véritable saignée pour un pays si long et si étroit de 8800000 habitants en 1973. Même si cela n'est pas reconnu officiellement, l'exil fut sans 
l'exil, voire aux enfants nés à l'étranger de parents exilés, souvent nés apatrides. Tous ont porté - et portent - le fardeau du déracinement comme un héritage familial mais aussi culturel, politique, social, et même parfois économique. La perte du pays s'est alourdie pour eux de la perte d'une identité sociale et d'un environnement familial et familier. Si, pour un certain nombre de jeunes, l'exil fut sans doute une chance unique de se former dans des écoles, des lycées puis des universités de qualité, la plupart ont ressenti le bannissement comme une punition d'autant plus injuste que les parents, source de toute stabilité émotionnelle et économique, devenaient eux-mêmes des êtres fragiles et maladroits confrontés à une nouvelle langue, à de nouveaux horizons urbains, à de nouvelles règles sociales et à de nouvelles professions plus ou moins improvisées pour surmonter la précarité.

Je fus l'un des enfants de l'exil et je porte les traces de cette violence politique. Une de ces traces est le sentiment que, comme le disait Vladimir Jankélévitch, "quelque chose nous incombe", que "ces morts, ces massacrés, ces tortu-

Revue Araucaria de Chile (c) D.R.

nul doute un des actes de violence les plus considérables mis en place par les militaires et leurs collaborateurs civils pour se débarrasser de potentiels adversaires. Parmi les exilés, il y a presque toutes celles et ceux qui furent torturés, dont les 3400 femmes violées.

Si la place dévolue à une préface me le permettait, je pourrais évoquer les exilés qui furent privés de nationalité et les exilés victimes de la répression alors qu'ils résidaient à l'étranger, ou encore l'interminable exil intérieur que signifie le retour dans un pays où l'ancien exilé n'a plus de place. Je voudrais m'en tenir aux plus jeunes, aux adolescents et aux enfants qui ont accompagné leurs parents dans rés, ces piétinés, ces offensés sont notre affaire à nous". L'exil est un élément fondateur de nos propres engagements politiques.

Je suis gré à la revue Hommes \& Migrations et aux organisateurs des trois tables rondes sur l'exil chilien en France au Musée de l'histoire de l'immigration et à la Maison de l'Amérique latine d'avoir contribué à mieux faire connaître ce que fut cette expérience, à l'occasion des commémorations des quarante ans du coup d’État qui renversa le gouvernement légitime du président Allende et qui détruisit durablement la démocratie au Chili. Nous y sommes sensibles à la région Île-de-France, parce que nous considérons avec Vladimir Jankélévitch que "le passé a besoin qu'on l'aide, qu’on le rappelle aux oublieux, aux frivoles et aux indifférents, car le passé a besoin de notre mémoire". 